\title{
Different carboxylic acid homodimers in self-assemblies of adducts of 3-carboxyphenoxyacetic acid with nitrogen containing compounds
}

\author{
KRAPA SHANKAR and JUBARAJ B BARUAH* \\ Department of Chemistry, Indian Institute of Technology Guwahati, Guwahati 781 039, Assam, India \\ e-mail: juba@iitg.ernet.in
}

MS received 23 December 2015; revised 25 February 2016; accepted 3 March 2016

\begin{abstract}
Different hydrogen bonded dimeric motifs of 3-carboxyphenoxyacetic acid (H2cpa) observed in the self-assemblies of salts or cocrystals of H2cpa with nitrogen containing compounds are discussed. Pyridinium salt of the H2cpa is a self-assembly of Hcpa with the pyridinium cation. The assembly is a combination of sub-assemblies of two Hcp anions with two pyridinium cations, in which the Hcpa cations are interconnected through carboxylate-carboxylic acid interactions. The cocrystals of H2cpa with isoquinoline or isonicotinamide are self-assemblies of hydrogen bonded dimers of H2cpa holding the respective guest molecule. However, the dimeric assemblies of H2cpa in these two cases are different from each other; the former cocrystal has carbony-hydroxyl type interactions in it whereas the latter cocrystal has unconventional dimeric subassemblies of H2cpa with hydroxyl-hydroxyl type hydrogen bond interactions. The cocrystal of H2cpa with theophylline has sub-assemblies of two H2cpa molecules interacting with two theophylline guest molecules, where the theophylline molecules are hydrogen bonded in two different ways.
\end{abstract}

Keywords. Dicarboxylic acid; bifurcated hydrogen bonds; self-assembly; cocrystal; homodimer; heterodimer.

\section{Introduction}

Seminal work of Desiraju on synthons ${ }^{1-3}$ and their subsequent applications in understanding supramolecular assemblies have made a big headway. ${ }^{4-12}$ Dunitz and Gavezzotti had suggested early examples to show the importance on understanding of the energetic of the interactions between molecules bonded by each synthon. ${ }^{13}$ On the other hand, Etter's rules have not only helped to provide qualitative pictures to prioritize on bond hierarchy to form a synthon but also provided a simple way to demarcate them through graph setnotations. ${ }^{14,15}$ Beside these, while forming supramolecular assemblies complicacies may arise from the competition of the constituent components forming selfassembly to form homomeric assembly or to form adduct by forming heteromeric assembly or combinations of both types of units to form self-assembly of adduct. ${ }^{16,17}$ For example, carboxylic acids can form neutral or partly deprotonated assembly in different ways as shown in scheme $1 .{ }^{18}$ In a latest analysis on different conformations of catemers of different carboxylic acids generated by hydroxyl-hydroxyl or carbonyl-hydroxyl type interactions (scheme 1) suggested the scope to discover new conformers in the assembly of carboxylic acids. ${ }^{19}$ Due to the directional nature of hydrogen bond, such

\footnotetext{
*For correspondence
}

conformers would decide the suitability of a specific guest molecule to bind with a host carboxylic acid. Furthermore, the directional properties of weak interactions have definite roles in soft materials ${ }^{20-23}$ framework structures, ${ }^{24-36}$ polymorphs, ${ }^{37}$ and self-assemblies. ${ }^{38-48}$ Hence, even to use any of the existing small building blocks with multiple hydrogen bond sites require prior analysis on different possibilities to form hydrogen bonds. With these points, we have chosen to study 3-carboxyphenoxyacetic acid (I) abbreviated as H2cpa. $\mathrm{H} 2 \mathrm{cpa}$ is a dicarboxylic acid having flexible and rigid arms along with an ether linkage. A close analysis on the published structure of 3-carboxyphenoxyacetic acid, has made us to realize that it forms dimeric assembly as illustrated in figure 1(a) by hydrogen bond interactions. ${ }^{49}$ This was a curious point to start a new study, as a carboxylic acid having multiple numbers of electronegative atoms such as oxygen atoms should easily remain as discrete units keeping the electronegative atoms apart. In other words, an assembly formed by such compounds should be possible to segregate easily by solvent molecules or guest molecules to provide different packing patterns which may lead to different arrangements. If the dimeric motifs are not dislodged by guest or solvent molecules, then also there are possibilities to reorganize the dimeric motifs to closely related structural motifs such as the ones shown in 


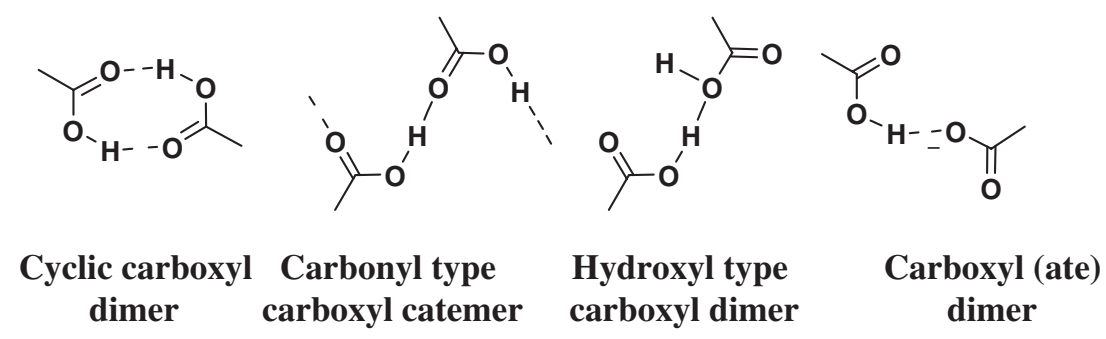

Scheme 1. Different assemblies of carboxylic acids.

figures $1 b-c$. These two motifs have not yet been explored. Discovery of such motifs may help to understand dislodging process of a dimeric assembly. Our anticipation was also based on our earlier observation where we obtained packing polymorphs of the (3-carboxymethoxy-naphthalen-2-yloxy)acetic acid, ${ }^{50}$ which is also a molecule comprised of linkages with carboxylic acid groups with intervening methylene groups. Thus, we set to study structures of different<smiles></smiles><smiles>O=C1CO[C@@H](Oc2cccc(C(=O)O)c2)[C@H](O)O1</smiles>

(b)<smiles>O=C1CO[C@H]2Oc3cccc(c3)C(=O)O[C@@H]3OC(=O)CO[C@H]3OC(=O)CO[C@H]2O1</smiles>

Figure 1. Different types of dimeric assemblies of 3carboxyphenoxyacetic acid formed by (a) carbonyl-hydroxyl type; (b) carbonyl-hydroxyl and hydroxyl-hydroxyl type and (c) hydroxyl-hydroxyl type interactions. cocrystals of $\mathrm{H} 2 \mathrm{cpa}$ with different nitrogen atom containing coformers as shown in figure 2.

\section{Experimental}

3-Carboxyphenoxyacetic acid ${ }^{49}$ was prepared by literature procedure. The cocrystals were obtained by mixing equimolar amounts of the respective carboxylic acid with the respective guest in methanol. After slow evaporation of such solution at ambient temperature $\left(\sim 27^{\circ} \mathrm{C}\right)$ in each case for two days, the crystals of respective cocrystals were obtained. Crystallisation of adduct from a solution of 3-carboxyphenoxyacetic acid with caffeine was unsuccessful from different solutions in solvents namely, THF, DMF, methanol, ethanol, chloroform and mixtures of these solvents. Powder XRD patterns of the salt and cocrystals were recorded and compared with the powder XRD pattern of each sample generated from respective crystallographic information file by using MERCURY software to establish their bulk purity and these are provided as Supporting Information.

X-ray single crystal diffraction data for the cocrystals and salts were collected at $298 \mathrm{~K}$ with Mo $\mathrm{K} \alpha$ radiation $(\lambda=0.71073 \AA)$ with the use of a Bruker Nonius SMART APEX CCD diffractometer equipped with a graphite monochromator and an Apex CCD camera.

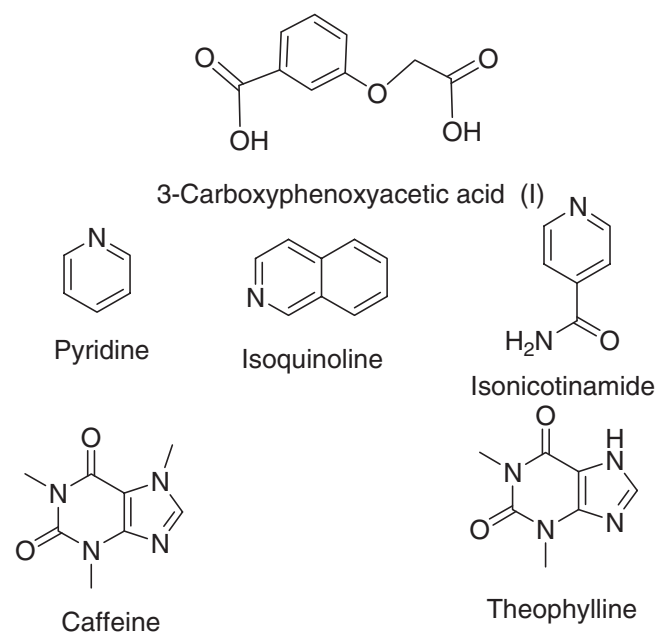

Figure 2. Host acid and the guest molecules. 
Table 1. Crystallographic parameters of the cocrystals/salt.

\begin{tabular}{|c|c|c|c|c|}
\hline Cocrystal/salt & II & III & IV & V \\
\hline Formula & $\mathrm{C}_{23} \mathrm{H}_{21} \mathrm{NO}_{10}$ & $\mathrm{C}_{27} \mathrm{H}_{23} \mathrm{~N} \mathrm{O}_{10}$ & $\mathrm{C}_{15} \mathrm{H}_{14} \mathrm{~N}_{2} \mathrm{O}_{6}$ & $\mathrm{C}_{16} \mathrm{H}_{16} \mathrm{~N}_{4} \mathrm{O}_{7}$ \\
\hline CCDC No. & 1432461 & 1432462 & 1417584 & 1417583 \\
\hline formula weight & 471.41 & 521.46 & 318.28 & 376.33 \\
\hline crystal system & Triclinic & Triclinic & Triclinic & Triclinic \\
\hline Space group & $\mathrm{P}-1$ & P-1 & $\mathrm{P}-1$ & $\mathrm{P}-1$ \\
\hline$a(\AA)$ & $7.5510(12)$ & $7.6699(6)$ & $7.7934(5)$ & $11.4675(7)$ \\
\hline$b(\AA)$ & $10.474(2)$ & $8.9654(8)$ & $8.6548(7)$ & $12.0693(8)$ \\
\hline$c(\AA)$ & $13.943(3)$ & $9.0521(8)$ & $10.7658(8)$ & $14.3043(9)$ \\
\hline$\alpha(\mathrm{deg})$ & $98.763(16)$ & $76.802(8)$ & $100.178(6)$ & $74.990(6)$ \\
\hline$\beta(\operatorname{deg})$ & $95.754(15)$ & $80.215(7)$ & $95.315(5)$ & $66.587(6)$ \\
\hline$\gamma(\mathrm{deg})$ & $97.518(15)$ & $89.098(7)$ & $92.523(6)$ & $64.482(6)$ \\
\hline$V\left(\AA^{3}\right)$ & $1072.4(3)$ & $597.03(9)$ & $710.30(9)$ & $1630.32(17)$ \\
\hline$Z$ & 2 & 1 & 2 & 4 \\
\hline$\rho_{\text {calc }} \cdot\left(\mathrm{g} \cdot \mathrm{cm}^{-3}\right)$ & 1.460 & 1.450 & 1.488 & 1.533 \\
\hline$\mu\left(\mathrm{mm}^{-1}\right)$ & 0.116 & 0.112 & 0.117 & 0.123 \\
\hline$F(000)$ & 492 & 272 & 332 & 784 \\
\hline reflns collected & 7327 & 3986 & 8581 & 9261 \\
\hline reflns unique & 3879 & 2156 & 2510 & 5597 \\
\hline \multirow[t]{3}{*}{ Ranges (h, k, l) } & $-8 \leq \mathrm{h} \leq 9$ & $-9 \leq \mathrm{h} \leq 9$ & $-9 \leq \mathrm{h} \leq 9$ & $-13 \leq \mathrm{h} \leq 13$ \\
\hline & $-12 \leq \mathrm{k} \leq 12$ & $-10 \leq \mathrm{k} \leq 10$ & $-10 \leq \mathrm{k} \leq 10$ & $-14 \leq \mathrm{k} \leq 13$ \\
\hline & $-16 \leq 1 \leq 16$ & $-10 \leq 1 \leq 10$ & $-12 \leq 1 \leq 12$ & $-14 \leq 1 \leq 16$ \\
\hline Completeness to $2 \theta$ & 99.7 & 99.5 & 97.4 & 99.7 \\
\hline $\operatorname{GOF}\left(F^{2}\right)$ & 1.099 & 0.958 & 1.126 & 1.331 \\
\hline $\mathrm{R}_{1}[I \geq 2 \sigma(I)]$ & 0.0817 & 0.0442 & 0.0562 & 0.0485 \\
\hline $\mathrm{wR}_{2}[\bar{I} \geq 2 \sigma(I)]$ & 0.1628 & 0.1057 & 0.1024 & 0.0961 \\
\hline $\mathrm{R}_{1}$ (all data) & 0.1684 & 0.0619 & 0.1075 & 0.0717 \\
\hline$w_{2}$ (all data) & 0.2049 & 0.1253 & 0.1160 & 0.1328 \\
\hline Largest diff peak/hole $\left(\mathrm{e} \AA^{-3}\right)$ & $0.580 /-0.262$ & $0.146 /-0.211$ & $0.373 /-0.216$ & $0.320 /-0.326$ \\
\hline
\end{tabular}

SMART software was used for data collection and also for indexing the reflections and determining the unit cell parameters. Data reduction and cell refinement were performed using SAINT and XPREP software. Multiscan empirical absorption corrections were carried out with the help of face-indexing. Structures were solved by direct methods using SHELXS-97 and were refined by full-matrix least-squares on $\mathrm{F}^{2}$ using SHELXL-97. The crystallographic parameters are listed in the table 1 .

\section{Results and Discussion}

Slow evaporation of methanol solutions of 3carboxyphenoxyacetic acid monohydrate (I) and a guest chosen from a series of nitrogen containing compounds was carried out. From such crystallizations, crystals of the respective salt or cocrystal were obtained which are listed in table 2. The stoichiometry of each salt or cocrystal was found to be invariant of

Table 2. Dimeric assemblies in salt and cocrystals of 3-carboxyphenoxyacetic acid \#.

Guest molecule (abbreviation) $[\mathrm{pKa}$, (adduct type)] Composition (HPy).(HCarbophen). ( $\mathrm{H}_{2}$ Carbophen) (II)

Pyridine (Py) [5.14 (Salt)]

Isoquinoine (Iqn) [5.14 (Cocrystal)]

Isonicotinamide (Inic)[3.61,(Cocrystal)]

Theophylline (Thp) [1 and 8.81, (Cocrystal)]

( $\mathrm{H}_{2}$ Carbophen $)_{2}$.(Iqn) (III)

( $\mathrm{H}_{2}$ Carbophen).(Inic) (IV)
Types of catemers in the assembly (conformer symmetry)

One end carboxyl(ate), (AS)

Other end carbonyl type (AS-A)

Both end carbonyl type (AS-A)

$\left[\left(\mathrm{H}_{2} \text { Carbophen).(Tph) }\right]_{2}(\mathbf{V})\right.$
Both end hydroxyl type (AS-A)

Both end carbonyl type (AS-A)
Principal cyclic motif with heterocycle

Held by pyridinium cation

Held by disordered isoquinoline molecule

Held by homodimer of isonicotinamide

Held by theophylline.

\footnotetext{
${ }^{\circledR}$ Compounds were crystallized from solution in methanol. \# pKa $=4.25$ (in methanol)
} 
the molar proportions of the two components used in their preparations. This conclusion was reached on the basis of the powder XRD patterns of each crystalline sample obtained from different solutions under different conditions and comparison with the respective PXRD pattern generated from CIF. Furthermore, the integrations of the proton signals in the respective ${ }^{1} \mathrm{H}$ NMR spectra (provided as Supporting Information) of the salt or cocrystal was in excellent agreement with the stoichiometry given in table 2 .

Structures of each cocrystal and salt were determined. The packing pattern of the crystal structure of 3 -carboxyphenoxyacetic acid monohydrate ${ }^{49}$ is comprised of a self-assembly constituted by dimers formed between two acid molecules. H2cpa molecule has two carboxylic acid groups at two different non-equivalent locations, hence the molecule is unsymmetrical, and the end of the which has the carboxylic acid directly linked to phenyl ring may be designated as head and other end of carboxylic acid attached through ether link as tail. Then each dimer formed in the assembly may be described as assembly of two molecules in head to tail manner (figure 3a). Such dimers have carbonylhydroxyl interactions and possess a center of inversion and each side of the dimers has AS-A conformation ${ }^{19}$ (inset of figure $3 a$ ).

Pyridinium salt II consists of three components comprising of an acid molecule, a mono deprotonated acid molecule and a pyridinium cation (figure $3 \mathrm{~b}$ ). The selfassembly of the salt has dimeric motifs formed by interactions between carboxylic acid and carboxylate. These motifs interact with the pyridinium cation by $\mathrm{N}-\mathrm{H} \cdots \mathrm{O}$ interactions. One end of each dimer motif has a carboxyl(ate) catemer possessing AS conformer and the other side has a carbonyl type catemer comprising of AS-A conformer. These motifs are held to each other through $\mathrm{O}-\mathrm{H} \cdots \mathrm{O}$ interactions. The hydrogen bond parameters are listed in table 3.

The cocrystal III is a self-assembly of two carboxylic acid molecules with one isoquinoline molecule. From crystallographic point of view, it is a self assembly of dimer of H2cpa flanked by two halves of an isoquinoline molecule at two ends. There is a crystallographic disorder in the isoquinoline ring which was resolved by sharing $\mathrm{CH}$ and $\mathrm{N}$ atoms at two symmetry equivalent positions as illustrated in figure $3 \mathrm{c}$. Alternatively, the self-assembly may be described as an assembly of sub-assemblies of two carboxylic acid molecules holding one isoquinoline at one end. Due to such a disorder, isoquinoline nitrogen apparently bridges two neighboring dimeric assemblies of carboxylic acid molecules and forms a chain-like structure. The structure of the adduct shows short $\mathrm{H}(4) \cdots \mathrm{H}(4)$ contact between the carboxylic acid protons and this is due to disorder associated with hydrogen atom and can be resolved easily by sharing hydrogen atoms while solving the structure. But in X-ray crystallography, positions of the hydrogen atoms are sometimes nonrealistic; hence, we have not done so and left it as obtained without sharing the electron density of hydrogen to maintain the charge balance and also it does not make significant effect on our discussion on the selfassembling process. The heterodimers present in this cocrystal has resemblance with heterodimers observed in cocrystals formed between a carboxylic acid with pyridine, ${ }^{51-54}$ the difference being the half occupancy of nitrogen atoms. Pyridine and isoquinoline have similar pKa value (5.14), yet they bind in different ways to the same carboxylic acid $(\mathrm{pKa}=4.25)$. These two examples may be considered as exceptional examples to note as the differences of $\mathrm{pKa}$ between the acid and guest molecules being similar and small $(\sim 0.9)$, yet they show different behaviors towards the proton exchange process with the same acid, namely, H2cpa. However, one point is clear that due to the small difference between the respective $\mathrm{pKa}$ values there is uncertainty ${ }^{55}$ in observing uniform way for both to fall in same category namely, salts or cocrystals.

Nicotinamide and isonictinamide are well known coformer to form cocrystals with different dicarboxylic acids. ${ }^{56}$ Our attempts to prepare corystalline products from solution of H2cpa with nicotinamide or isonictinamide yielded crystals of cocrystal of H2cpa with isonicotinic acid, whereas the $\mathrm{H} 2 \mathrm{cpa}$ and nicotiamide were precipitated from the solution of the former combination without forming cocrystals. The cocrystal IV was formed by one $\mathrm{H} 2 \mathrm{cpa}$ molecule interacting with one isonicotinamide molecule but in practice the crystal structure has shown that it is a self-assembly comprising of sub-assemblies of dimer formed by two carboxylic acid molecules with dimers of two isonicotinamide molecules. The dimers formed between isonicotinamide molecules act as bridge between the dimers of $\mathrm{H} 2 \mathrm{cpa}$ through hydrogen bond interactions of carboxylic $\mathrm{OH}$ with pyridine nitrogen atom of isonicotinamide. The hydrogen bond patterns in the dimers formed between the two molecules of $\mathrm{H} 2 \mathrm{cpa}$ in this cocrystal is exceptional. It possesses hydroxyl-hydroxyl interactions at both the ends with AS-A conformations. The hydroxyl-hydroxyl type dicarboxylic acid motifs are relatively less in literature but the one with AS conformer is not known. ${ }^{18}$ Hence, this hydroxyl type carboxylic acid dimer possessing AS conformers is a new finding in dicarboxylic acid. The self assemblies formed by the pair of carboxylic acids are flanked by homodimeric assemblies formed between 

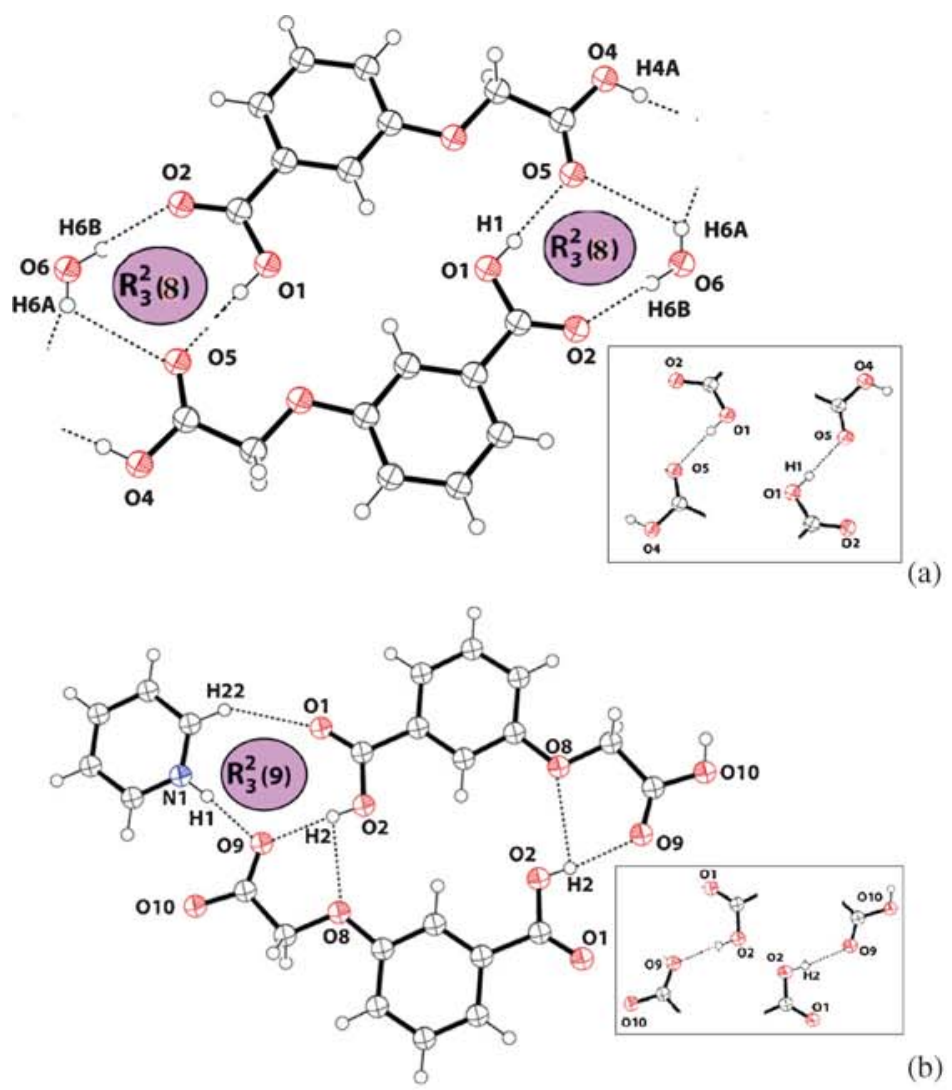

(b)
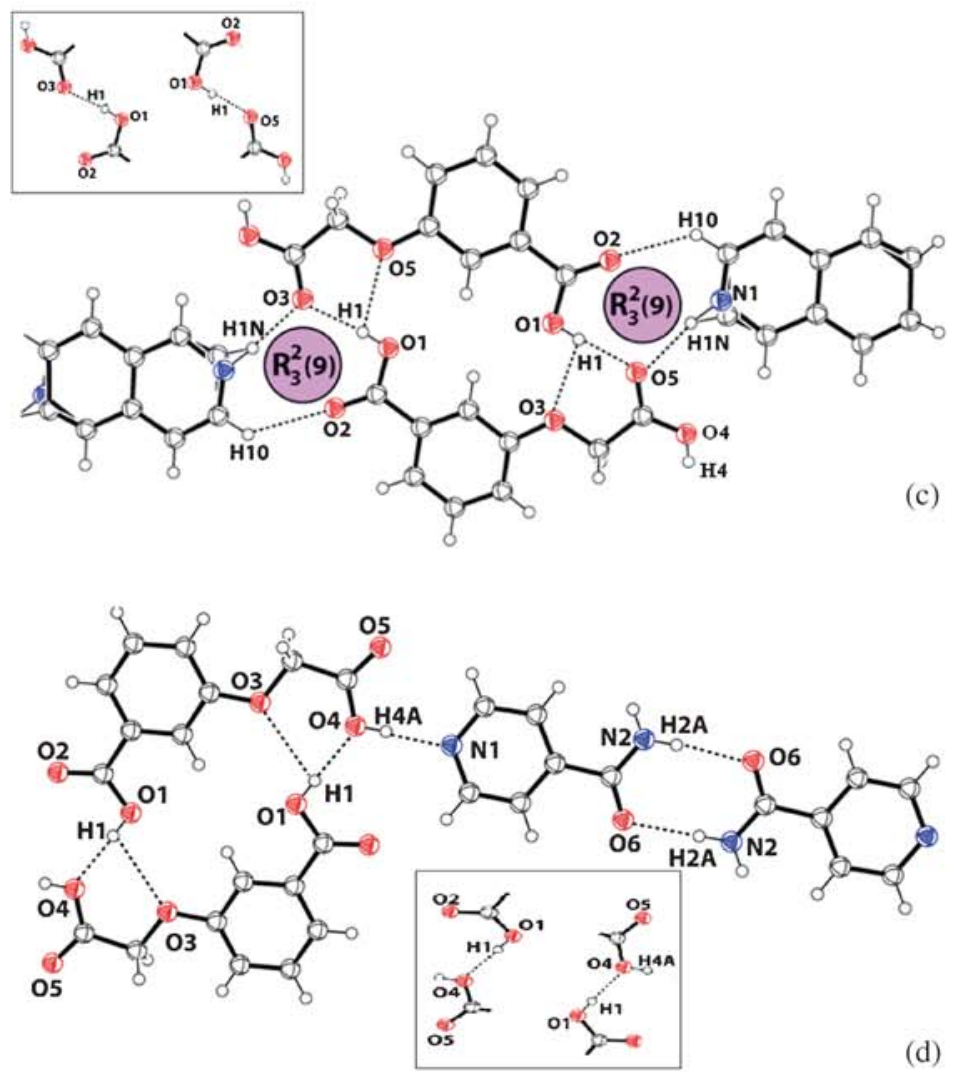

Figure 3. Self-assembly of (a) 3-carboxyphenoxyacetic acid monohydrate (I); (b) Pyridinium salt (II); (c) Cocrystal with isoquinoline (III); (d) Cocrystal with isonicotinamide (IV). Insets are the two catemers of carboxylic acid/ carboxylate motifs. 
Table 3. Hydrogen bond parameters of the salt and cocrystals.

\begin{tabular}{|c|c|c|c|c|c|}
\hline Cocrystal/salt & Bond (symmetry) & $\mathrm{d}_{\mathrm{DH}(\AA)}$ & $\mathrm{d}_{\mathrm{H} \cdots \mathrm{A}(\AA)}$ & $\mathrm{d}_{\mathrm{D} \cdots \mathrm{A}(\AA)}$ & $<\mathrm{D}-\mathrm{H} \cdots \mathrm{A}\left({ }^{\circ}\right)$ \\
\hline \multirow[t]{3}{*}{ II } & $\mathrm{N}(1)-\mathrm{H}(1) \cdots \mathrm{O}(9)[2-\mathrm{x}, 1-\mathrm{y}, 1-\mathrm{z}]$ & 0.86 & 1.86 & $2.719(6)$ & 176 \\
\hline & $\mathrm{O}(2)-\mathrm{H}(2) \cdots \mathrm{O}(9)[\mathrm{x}, \mathrm{y},-1+\mathrm{z}]$ & 0.82 & 1.86 & $2.673(4)$ & 172 \\
\hline & $\mathrm{C}(22)-\mathrm{H}(22) \cdots \mathrm{O}(1)[2-\mathrm{x}, 1-\mathrm{y}, 1-\mathrm{z}]$ & 0.93 & 2.45 & $3.277(7)$ & 148 \\
\hline \multirow[t]{4}{*}{ III } & $\mathrm{O}(1)-\mathrm{H}(1) \cdots \mathrm{O}(5)[-\mathrm{x}, 1-\mathrm{y},-\mathrm{z}]$ & 0.82 & 1.88 & $2.695(2)$ & 174 \\
\hline & $\mathrm{N}(1)-\mathrm{H}(1 \mathrm{~N}) \cdots \mathrm{O}(5)[-\mathrm{x}, 1-\mathrm{y}, 1-\mathrm{z}]$ & $0.99(4)$ & $2.00(4)$ & $2.981(15)$ & $169(4)$ \\
\hline & $\mathrm{O}(4)-\mathrm{H}(4) \cdots \mathrm{O}(4)[-\mathrm{x}, 2-\mathrm{y}, 1-\mathrm{z}]$ & $0.85(8)$ & $1.70(8)$ & $2.539(2)$ & $169(8)$ \\
\hline & $\mathrm{C}(10)-\mathrm{H}(10) \cdots \mathrm{O}(2)[\mathrm{x}, \mathrm{y}, 1+\mathrm{z}]$ & $0.97(3)$ & $2.45(3)$ & $3.130(4)$ & $127(2)$ \\
\hline \multirow[t]{4}{*}{ IV } & $\mathrm{O}(1)-\mathrm{H}(1) \cdots \mathrm{O}(3)[-\mathrm{x}, 2-\mathrm{y}, 1-\mathrm{z}]$ & 0.82 & 2.55 & $2.09(3)$ & 108 \\
\hline & $\mathrm{O}(1)-\mathrm{H}(1) \cdots \mathrm{O}(4)[-\mathrm{x}, 2-\mathrm{y}, 1-\mathrm{z}]$ & 0.82 & 1.85 & $2.671(3)$ & 178 \\
\hline & $\mathrm{N}(2)-\mathrm{H}(2 \mathrm{~A}) \cdots \mathrm{O}(6)[2-\mathrm{x}, 1-\mathrm{y}, 1-\mathrm{z}]$ & 0.86 & 2.04 & $2.892(3)$ & 172 \\
\hline & $\mathrm{O}(4)-\mathrm{H}(4 \mathrm{~A}) \cdots \mathrm{N}(1)[\mathrm{x}, 1+\mathrm{y}, 1+\mathrm{z}]$ & 0.82 & 1.78 & $2.599(3)$ & 178 \\
\hline \multirow[t]{5}{*}{ V } & $\mathrm{O} 1-\mathrm{H} 2 \cdots \mathrm{O} 10[\mathrm{x},-1+\mathrm{y}, \mathrm{z}]$ & 0.82 & 1.99 & $2.802(4)$ & 173 \\
\hline & $\mathrm{O} 4-\mathrm{H} 4 \cdots \mathrm{N} 3[1-\mathrm{x}, 1-\mathrm{y}, 1-\mathrm{z}]$ & 0.82 & 1.83 & $2.654(3)$ & 177 \\
\hline & $\mathrm{O} 6-\mathrm{H} 7 \ldots \mathrm{O} 5[\mathrm{x}, 1+\mathrm{y}, \mathrm{z}]$ & 0.82 & 1.94 & $2.755(3)$ & 175 \\
\hline & O9-H9. . O11[x,y,z] & 0.82 & 1.75 & $2.550(3)$ & 165 \\
\hline & N8-H8AB $\cdots$ O10 [x,y,z] & $1.01(4)$ & $2.02(4)$ & $3.007(4)$ & 166(4) \\
\hline
\end{tabular}

two isonicotinamide molecules. The homodimer of the isonicotinamides comprises of $\mathrm{R}_{2}^{2}(8)$ motifs ${ }^{14,15}$ having $\mathrm{N}-\mathrm{H} \cdots \mathrm{O}$ interactions as shown in the figure 3(d). Amide molecules generally form self-assemblies by forming homodimers or cocrystals with carboxylic acids by forming heterodimers. ${ }^{57}$ The present example of cocrystal IV is an assembly formed by combination of such homodimers and heterodimers. The major difference in the cocrystal of $\mathrm{H} 2 \mathrm{pca}$ with isonicotinamide with the cocrystal with isoquinoline arises from the type of donor-acceptors involved in the hydrogen bonds in their constituent dimers between the acid molecules.

Theophylline is generally a good guest molecule to form cocrystals with carboxylic acids through $\mathrm{O}$ $\mathrm{H} \cdots \mathrm{N}$ interactions. ${ }^{58-62}$ Different possibilities to form heterodimers and homodimers shown in the figures $4 \mathrm{~b}-$ e in assemblies of carboxylic acids with theophylline were illustrated by MacGillivray and his coworkers. ${ }^{63}$ In this study, we find that the compound H2cpa forms easily 1:1 cocrystal (V) with theophylline. The crystal structure has shown that the self assembly of the cocrystal is an assembly of assemblies formed by 1:1 cocrystals. Each dimer formed by two H2cpa molecules hydrogen bonds two theophylline molecules at two ends through hydrogen bonds in different manners. The dimers formed by two molecules of H2cpa are identical to the parent compound I. They have carbonyl type catemers with AS-A conformations. The different ways of forming hydrogen bonds by two independent theophylline molecules with $\mathrm{H} 2 \mathrm{cpa}$ dimer may be attributed to competition between the theophylline molecules to form homodimer or to remain a single unit by interacting with $\mathrm{H} 2$ cpa by forming heterodimer. It was earlier suggested that the energy of a motif can be an important factor for observing a particular synthon in a self-assembly. ${ }^{13}$ Accordingly, we have done DFT calculations at b3lyp/6-31++g(d,p) level to find out the difference between the two heterodimers shown in the figures $4 \mathrm{e}$ and $4 \mathrm{f}$ having $\mathrm{R}=\mathrm{H}$. It is found that the heterodimer shown in figure $4 \mathrm{e}$ is more stable by energy $6.75 \mathrm{~kJ} / \mathrm{mole}$. This energy is comparable to very weak hydrogen bond interactions. As a consequence of the small energy difference, a mild acid such as H2cpa compromises to accommodate either form (monomer or dimeric motifs) of theophylline in the lattice. Hence, one side of the dimer of the H2cpa molecule holds a theophylline through a $\mathrm{R}_{2}^{2}(9)$ type ${ }^{14,15}$ synthon involving $\mathrm{O}-\mathrm{H} \cdots \mathrm{O}$ and $\mathrm{N}-\mathrm{H} \cdots \mathrm{O}$ interactions and remains as a single molecule, whereas the other end has $\mathrm{N}-\mathrm{H} \cdots \mathrm{O}$ as the major interaction to hold a dimer formed between two theophylline molecules. Hence, we find an exceptional example within a two component cocrystal to have two different synthons independently in the same cocrystal.

Theophylline and caffeine are structurally related compounds; cocrystal of 3-carboxyphenoxyacetic acid with theophylline was easily formed but not with caffeine. Attempted crystallization of cocrystals, if any, from the solutions of 3-carboxyphenoxyacetic acid and caffeine from different solvents was not successful, but such solutions yielded the crystals of the parent compounds. 


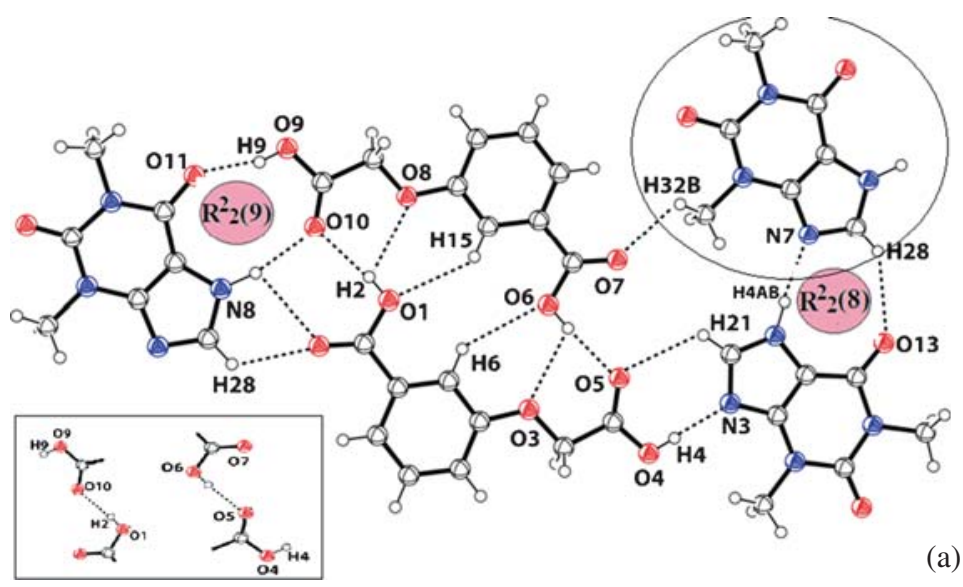

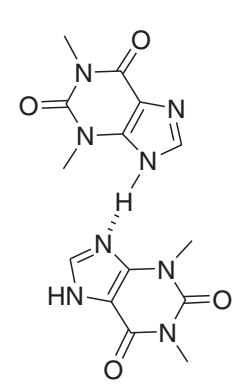

(b)

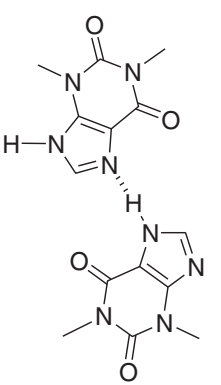

(c)

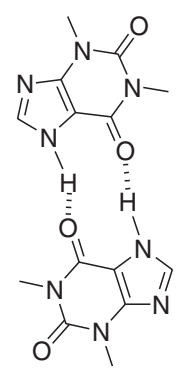

(d)<smiles>Cn1c(=O)c2c(ncn2C)n(C)c1=O</smiles>

(e)

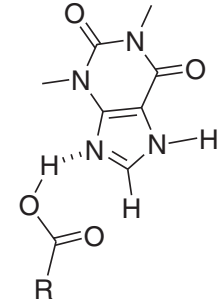

(f)

Figure 4. (a) A portion of the self-assembly of the cocrystal $\mathbf{V}$ formed between $\mathbf{I}$ with theophylline (the circled portion is from another repeat unit) (b)-(d) Generally formed homodimers of theophylline; (e)-(f) Heterodimers in cocrystals of theophylline with carboxylic acids.

\section{Conclusions}

In conclusion, homodimers present in the self assembly of $\mathrm{H} 2 \mathrm{cpa}$ are adjusted in different ways by nitrogen containing guest molecules. As a result of competition to retain the dimeric self-assembly between a pair of isonicotinamide or $\mathrm{H} 2 \mathrm{cpa}$ molecules, and to meet the packing requirements to construct a tight packed structure, slight reorganization of hydrogen bonded motif originally present in the homodimers formed between two H2cpa molecules took place. Hence, unconventional hydroxyl-hydroxyl type hydrogen bonds were observed in the cocrystal of H2cpa with isonicotinamide. On the other hand, two symmetry independent theophylline molecules held across the two ends of a dimeric assembly formed by two $\mathrm{H} 2 \mathrm{cpa}$ molecules are attributed to the competition of theophylline molecules to retain cyclic hydrogen bonded homodimers versus formation of cyclic type hydrogen bonded heterodimers between theophylline and carboxylic acid. Thus, this study depicts examples showing the importance of inter-motif interactions beyond synthons in non-covalent synthesis.

\section{Supplementary information (SI)}

The crystallographic information files are deposited to Cambridge Crystallographic Database and have the CCDC numbers 1432461, 1432462, 1417584, 1417583 (for II-V) respectively. The powder XRD patterns of the salt and cocrystal II-V and the packing patterns and spectroscopic details are given in Supplementary Information which is available at www.ias.ac.in/chemsci.

\section{References}

1. Desiraju G R 1995 Angew. Chem. Int. Ed. 342311

2. Desiraju G R 1997 Chem. Commun. 1475

3. Desiraju G R 2013 J. Am. Chem. Soc. 1359952

4. Mukherjee A, Tothadi S and Desiraju G R 2014 Acc. Chem. Res. 472514

5. Dunitz J D and Gavezzotti A 2012 Cryst. Growth Des. 125873

6. Thakur T S and Desiraju G R 2008 Cryst. Growth Des. 84031

7. Almarsson $\mathrm{O}$ and Zaworotko M J 2004 Chem. Commun. 1889

8. Aakeroy C B, Beatty A M and Helfrich B A 2001 Angew. Chem., Int. Ed. 403240 
9. MacGillivray L R, Reid J L and Ripmeester J A $2000 \mathrm{~J}$. Am. Chem. Soc. 1227817

10. Thalladi V R, Weiss H C, Blaser D, Boese R, Nangia A and Desiraju G R 1998 J. Am. Chem. Soc. 1208702

11. Sarma J A R P and Desiraju G R 2002 Cryst. Growth Des. 293

12. Desiraju G R 1996 Acc. Chem. Res. 29441

13. Dunitz J D and Gavezzotti A 2012 Cryst. Growth Des. 125873

14. M C Etter 1990 Acc. Chem. Res. 23120

15. Etter M C, McDonald J C and Bernstein J 1990 Acta Crystallogr. B46 256

16. Shishkin O V, Zubatuyuk R I, Svitlana V, Dyakonenko V V and Medviediev V V 2014 Phys. Chem. Chem. Phys. 166773

17. Cruz-Huerta J, Salazar-Mendoza D, Henandez-Paredes J, Hernandez I F and Hopfl H 2012 Chem. Commun. 48 4241

18. Braga D, Grepioni F and Desiraju G R 1998 Chem. Rev. 981375

19. D'Ascenzo L and Auffinger P 2015 Acta Cryst. B71 164

20. Ishifuji M, Mitsuishi M and Miyashita T $2009 \mathrm{~J}$. Am. Chem. Soc. 1314418

21. Otsubo Y, Wakabayashi J, Ohara S, Yamamoto H, Matsuzaki H, Okamoto K, Nitta T, Uruga K and Kitagawa H 2011 Nat. Mater. 10291

22. Ariga K, Hill J P and Ji Q 2007 Phys. Chem. Chem. Phys. 92319

23. Vijayaraghavan A 2013 Phys. Status Solidi 250b 2550

24. Cook T R, Zheng Y -R and Stang P J 2013 Chem. Rev. 113734

25. Fujita M, Yazaki K and Ogura J 1990 J. Am. Chem. Soc. 1125645

26. Zangrando E M, Casanova E and Alessio J 2008 Chem. Rev. 1084979

27. Wurthner F, You C C and Saha-Moller C R 2004 Chem. Soc. Rev. 33133

28. Thanasekaran $\mathrm{P}$, Liao $\mathrm{R} \mathrm{T}$, Liu $\mathrm{Y} \mathrm{H}$, Rajendran $\mathrm{T}$, Rajagopal S and Lu K L 2005 Coord. Chem. Rev. 249 1085

29. Ward M D 2009 Chem. Commun. 4487

30. Olenyuk B, Whiteford J A, Fechtenkotter A and Stang P J 1999 Nature 398796

31. Paquette L A, Balogh D W, Usha R, Kountz D and Christoph G G 1981 Science 211575

32. Leininger S, Olenyuk B and Stang P J 2000 Chem. Rev. 100853

33. Li S S, Northrop B H, Yuan Q H, Wan L J and Stang P J 2008 Acc. Chem. Res. 42249

34. Muller A, Das S K, Talismanova M O, Bogge H, Kogerler P, Schmidtmann M, Talismanov S S, Luban M and Krickemeyer E 2002 Angew. Chem., Int. Ed. 41579

35. Perry J J, Kravtsov C, McManus G J and Zaworotko M J 2007 J. Am. Chem. Soc. 12910076
36. Newkome G R, He E F and Moorefield C N 1999 Chem. Rev. 991689

37. Karmakar A and Baruah J B 2008 J. Mol. Struct. 888 197

38. Weiss R G 2014 J. Am. Chem. Soc. 1367519

39. Husain A, Parveen R and Dastidar P 2015 Cryst. Growth Des. 155075

40. Piepenbrock M-O M, Lloyd G O, Clarke N and Steed J W 2010 Chem. Rev. 1101960

41. Sahoo P, Chakraborty I and Dastidar P 2012 Soft Matter 82595

42. Estroff L A and Hamilton A D 2000 Angew Chem. Int. Ed. 393447

43. Balzani V, Ceroni P, Maestri M and Vicinelli V 2003 Curr. Opin. Chem. Biol. 7657

44. Dsouza R N, Pischel U and Nau W M 2011 Chem. Rev. 1117941

45. Hargrove A E, Nieto S, Zhang T, Sessler J L and Anslyn E V 2011 Chem. Rev. 1116603

46. Wimbush K S, Reus W F, van der Wiel W G, Reinhoudt D N, Whitesides G M, Nijhuis C A and Velders A H 2010 Angew. Chem. Int. Ed. 4910176

47. Pluth M D, Bergman R G and Raymond K N 2009 Acc. Chem. Res. 421650

48. Fiedler D, Leung D H, Bergman R G and Raymond K N 2004 Acc. Chem. Res. 38349

49. Gu C J, Liu J-W, Huo L-H, Zhao H, Zhao J-G and Gao S 2004 Acta. Crystallogr. E60 o760

50. Karmakar A and Baruah J B 2008 J. Mol. Struct. 888 197

51. Singh D, Bhattacharyya P and Baruah J B 2010 Cryst. Growth Des. 10348

52. Rajput L, Santra R and Biradha K 2010 Aust. J. Chem. 63578

53. Santra R, Ghosh N and Biradha K 2008 New J. Chem. 1673

54. Singh D and Baruah J B 2012 Cryst. Growth Des. 12 3169

55. Bhogala B R, Basavoju S and Nangia A 2005 CrystEngComm 7551

56. Das B and Baruah J B 2011 Cryst. Growth Des. 115522

57. Vishweshwar P, Nangia A and Lynch V M 2003 Cryst. Growth Des. 3783

58. Das B and Baruah J B 2011 Cryst. Growth Des. 11278

59. Abourahma H, Urban J M, Morozowich N and Chan B 2012 CrystEngComm 146163

60. Sarma B and Saikia B 2014 CrystEngComm 154753

61. McNamara D P, Childs S L, Giordano J, Iarriccio A and Cassidy J 2014 Cryst. Growth Des. 145318

62. Set M S, Mannion R, O’Donnell E and Park A 2006 Pharm. Res. 231888

63. Bucar D F, Henry R F, Zhang G G Z and MacGillivray L R 2014 Cryst. Growth Des. 145318 